\title{
How COVID-19 shock will drive the economy and climate? A data-driven approach to model and forecast
}

\author{
Adnan Khurshid $^{1,2}$ (D) Khalid Khan ${ }^{3}$ \\ Received: 28 April 2020 / Accepted: 15 June 2020 / Published online: 8 September 2020 \\ (C) Springer-Verlag GmbH Germany, part of Springer Nature 2020
}

\begin{abstract}
The pandemic shock puts the world on quarantine and paused economic operations that affected energy consumption and economic output. This study analyzed the impact of the COVID-19 shock on GDP, energy consumption, and climate change then forecasted the situation until 2032 using the system dynamic modeling approach. The outcomes reveal that the pandemic shock will decrease the growth by $1.3 \%$ in 2020 and $1.32 \%$ in 2021 . The current shortfall, low energy consumption, and delay in completion of energy-related projects can reduce the GDP by $5.2 \%$ in 2020 . The effect will penetrate the system and will cause further losses in the upcoming years. The energy consumption and quarantine situation will improve the climate situation and drop the average temperature by 0.049 and $0.021^{\circ} \mathrm{C}$ in 2020 and 2021 . The aggregate demand and supply side measures such as national spending, lowering the lending rate, and cuts in income taxes can help in diffusing the situation. The government should start operations on ongoing energy projects, give relaxation to SME's with tight SOPs to secure jobs, and prevent possible GDP losses. The decline in oil prices provides an opportunity to cut fossil fuel subsidies and implement a carbon pricing mechanism.
\end{abstract}

Keywords COVID-19 shocks · Energy consumption $\cdot$ Economic growth $\cdot$ Climate change $\cdot$ Energy shortfal

\section{Introduction}

An uninterrupted energy supply is extremely crucial for sustainable economic development (Atif and Siddiqi 2010). It is believed that energy is the lifeblood of the economy, which is subject to policies and market forces of demand-supply. It is equally important for both developed and developing economies and for industrial sectors to achieve economic development and social stability (Rehman and Deyuan 2018). The consistencies of energy-related policies are dependent on economic, political, and environmental factors that decide the

Responsible editor: Nicholas Apergis

Khalid Khan

Shah_khan884@yahoo.com

Adnan Khurshid

adnankhurshid83@gmail.com

1 School of Economics and Management, Zhejiang Normal University, Jinhua, Zhejiang, China

2 School of Economics and Business, North China University of Technology, Beijing, China

3 School of Finnace, Qilu University of Technology, Jinan, China technology to achieve future demand. However, the gap between demand and supply influences transportation sectors, health, education institutions, manufacturing industries, and agriculture. The aggregate impact is reflected in declining business and investors' confidence, which results in the fall of output (Mahmood and Kanwal 2017). Uncertainty shocks have severe consequences for the energy supply and can widen the gap between demand and supply, which ultimately harms economic growth.

Pakistan is facing severe energy deficiency, and more than 212 million people lack access to a sustainable and reliable supply of energy (International Finance Corporation [IFC] 2017). The economic development of energy consumption has a strong mutual relationship as the energy demand increases the GDP growth and vice versa (Javid and Qayyum 2014). The rise in electricity is attributed to the GDP growth, industrialization, and electrification of villages (World Bank 2017). However, the country is facing a severe power crisis as a result of the failure of effective policy, leading to poor economic performance. Furthermore, this failure of polices in the energy sector results in power shortages and results in a GDP loss of $2.4 \%$, unemployment and exports of 0.53 million (Aziz et al. 2010). The annual demand for electricity rises by $9 \%$ as compared with a $7 \%$ growth in supply, which creates a 
gap (Rehman and Deyuan 2018). The power sectors are never able to catch up with the increasing energy demand. Therefore, the gap is getting wider to date. The electric shortfall leads to $2.5 \%$ of GDP loss per year, $40 \%$ of industries are closed, and about $7.5 \%$ of the workforce is unemployed (Aziz and Ahmad 2015). Pakistan's per capita electricity consumption increased from $376 \mathrm{kWh}$ in 2013 to $473 \mathrm{kWh}$ in 2018, about a quarter of the global average (Economic Survey 2018). However, as per the national transport and distribution report, per capita consumption was reported $522 \mathrm{kWh}$.

The country is already struggling to meet the energy demand for sustainable economic growth. This unfortunate situation can become worse with COVID 19 shocks- a global pandemic which results in the standstill of the global economy. Governments and major financial institutions are predicting the huge economic cost of the pandemic. This increases uncertainty levels and hints at the emergence of a global recession. The gap between the demand and supply of energy will increase due to the prevailing uncertain situation and low economic growth. The World Bank has predicted that Pakistan's economy will shrink by $1.2 \%$ in the current year and the shock can also be visible in the future. This falling GDP may cause a decline in the demand for energy due to low industrial, manufacturing, business, and education sectors' demand. The global value chain will disrupt, and the exporters may be unable to meet their orders. Furthermore, most of the industrial raw materials are imported from European countries and China, which have been shut down, and this makes the usual flow of goods difficult. Moreover, small- and medium-sized businesses may experience bankruptcy, which results in higher unemployment and hyperinflation in the country. The slowing down of the economy can result in low demand for energy, which implies declining economic activities, which ultimately reflects in the shrinking of economic growth. Thus, the mutual relationship energy consumption and GDP growth are enormously vulnerable to COVID-19. The situation is exceptionally vital to be investigated in the aftermath of the COVID-19, and effective policy recommendations can have a great impact.

The present study is undertaken with the following objectives. First, we examine GDP growth's impact on energy consumption and vice versa. Second, this relationship is examined in the context of the COVID-19 uncertainty shock. It evaluates the negative consequence of GDP growth and the ultimate effect on energy consumption. Thirdly, we forecast whether the shock will have protracted repercussions for the GDP growth and energy consumption in the future. Lastly, we aim to determine the way in which energy consumption will affect climate change in the country. Moreover, the study has valuable contributions to both literature and policymakers in the following ways. First, the study provides insightful information about energy consumption, demand, and GDP growth in the context of the COVID-19 shock. It shows the patterns of relationship between GDP growth and energy consumptions by covering various contributing elements such as environmental population growth and temperature. Second, the forecasting may give a clear picture of the impact and intensity of the shocks. Similarly, the prediction period of the shock can help policymakers and the government to devise effective policies to mitigate the strength of the shock. Lastly, in terms of methodology, the study has significant value in the literature. The system dynamic model is capable of evaluating the relationship and forecasting it in the future. The current study assesses the COVID-19 pandemic shock on GDP and energy consumption and then forecasts it until 2032 by means of a system dynamic modeling approach. The results show that shock can shrink the GDP growth rate by $1.35 \%$ in 2020 and the lack of proactive policies can make this adverse impact linger until 2029. The pandemic shock will reduce the GDP by $1.32 \%$ in 2021 and with an annual average of $1.25 \%$ in the next 4 years. Likewise, the shocks will delay the energy projects and will induce GDP loss until 2028. However, lockdown and energy consumption will positively affect climate change. The government should increase spending and reduce lending rates and corporate and income taxes. The government should spare some resources to import testing kits and diagnostic machines, establish labs in every region, lockdown the affected areas, and give relaxation to the industries of the less affected regions with tight SOPs. Moreover, special attention, such as financial support, should be given to SMEs, which can save jobs and reduce possible GDP losses.

The remaining of this paper is organized in the following manner. The "Literature review" section reviews the literature. Data and methodology are outlined in the "Date and methodology" section. The "Empirical outcomes" section analyzes the results, and the "Conclusion and policy implications" section concludes.

\section{Literature review}

The existing literature consists of numerous studies that analyze the relationship between energy consumption and economic growth. Ozturk et al. (2010) found that energy consumption and GDP are correlated in the long run in all three income groups. Furthermore, there is a unidirectional causality running from GDP to energy consumption for low-income countries, while bidirectional causality is running from energy consumption to GDP for middle-income countries. Chen et al. (2012) concluded that economic growth and energy consumption are subjected to numerous factors in 174 countries. $\mathrm{Lu}$ (2017) studied the existing relationship between economic growth and energy consumption in Taiwan and observed a long-term association and bidirectional causality. Gozgor et al. (2018) confirmed that energy consumption and higher economic growth are positively related in OECD 
countries. Shahbaz et al. (2018) showed that energy consumption and economic growth have a positive relationship in top economies. Moreover, the relationship is weak in the lower quantile for China, India, Germany, and France. In comparison, a similar association is noted in the higher quantile for the United States, Canada, Brazil, and South Korea.

There is a strand of literature in the connection between uncertainty shocks and growth. Lensink et al. (1999) evaluated economic policy uncertainty in 138 developing countries and remarked a negative association between uncertainty and economic growth. Asteriou and Price (2005) showed that investment uncertainty reduces the investment as well as growth in 59 industrial and developing countries between 1966 and 1992. Sušjan and Redek (2008) analyzed the nexus between uncertainty shocks and growth and showed a negative relationship between uncertainty and GDP. Christensen et al. (2018) showed the possibility of greater climate changes indicating substantial higher uncertainty. Rathnayaka et al. (2018) find bidirectional causality between GDP and energy consumption in China, which has a significant contribution to policymakers. Hao et al. (2018) evaluated rural energy consumption and GDP in China using a vector error correction model. The findings indicated a long-term bidirectional relationship between GDP and energy consumption.

The spread of COVID-19 puts the world on quarantine, blocked industrial roads, and stopped the mobility, which reduced the energy consumption and $\mathrm{CO} 2$ emission (WIRED 2020). Due to pandemic 2.6, bn metric tons of carbon were never emitted, that is, $8 \%$ of the estimated value of the year (Bloomberg Green 2020). The GDP and per capita growth lead towards environmental degradation, whereas pandemics and disruption in economic activities have a contrary impact on climate (World Bank 2020; das Neves Almeida et al. 2017; Ali et al. 2019). Akram (2013) and Akram and Hamid (2015) examined the bilateral relationship among GDP, energy consumption, industrial output, and climate change. The outcomes revealed that these factors have caused the temperature to rise in Pakistan and have a detrimental effect on the environment. Similarly, the industrial production and energy consumption for transportation cause environmental degradation and affect ecological footprints (Mgbemene 2011; Qiang et al. 2019). Nordhaus (2013) showed that the world bears $2.6 \%$ GDP losses due to global warming and $3{ }^{\circ} \mathrm{C}$ rise causes $0.25 \%$ GDP losses in the USA. Li et al. (2019) studied the impact of energy consumption on temperature and climate change. The outcomes showed that in Shanghai during summer, the temperature rises by $1^{\circ}$ due to a $14.5 \%$ increase in energy consumption. Akpan and Akpan (2012) concluded that the use of fossil fuels increased the energy supply and consumption that contributed to $80 \%$ of greenhouse gas emission. Alfredsson (2004) noticed that the use of green energy consumption will reduce the black energy usage and have a positive effect on the climate.
We also consider some studies about uncertainty and economic growth and energy consumption in Pakistan. Siddiqui (2004) concluded that higher economic growth is caused by energy expansion and vice versa in Pakistan. Atif and Siddiqi (2010) analyzed the association between energy consumption and GDP in Pakistan from 1971 to 2007. The findings suggested the long-run relationship and the unidirectional causality running from energy consumption to GDP. Ashraf et al. (2013) find a unidirectional causality association between GDP and electricity consumption in the long run at the aggregate level, which stimulates a higher demand for energy consumption. Mahmood and Kanwal (2017) showed a long-run association between GDP and energy consumption, as well as the existence of causality running from GDP to energy intensity. Moreover, the industrial service sectors in the GDP may increase energy intensity. Rehman and Deyuan (2018) analyzed the role of GDP in energy consumption in Pakistan using an autoregressive distributed lag (ARDL). The results demonstrated that energy usage and urban population growth have a significant impact on economic growth. Similarly, the authors indicated a negative impact of the rural population and rural population growth on the economic growth in Pakistan. Fatima and Waheed (2014) noticed that economic uncertainty not only shrinks investment and growth but also affect future policy decisions. Farooq and Yasmin (2017) used the autoregressive distributed lag method to evaluate the uncertainty impact on growth. The results suggest that fiscal uncertainty hurts economic growth.

The previous literature examines the relationship between energy consumption GDP and economic uncertainty. We summarize this literature in the following ways. First, most of these studies evaluate the nexus between GDP and energy consumption that as the GDP increases, so does the energy consumption in the same direction and vice versa. A higher rate of economic growth will increase the demand for energy consumption as a result of rising population and industries. Second, uncertainty reduces investment, which has a negative impact on economic growth and the future outlook of an economy. Economic growth is extremely vulnerable to economic policy uncertainty and results in a negative impact on overall economic development. Moreover, the previous literature lacks contributions which cover uncertainty shocks on the energy consumption of their ultimate impact on the GDP. Lastly, in terms of the econometric methods, all the above studies have used traditional techniques which have drawbacks to evaluate the future trends of the uncertainty shock on the economic growth and energy consumption. These methods are best suited to evaluate Granger causality in the short and long run. However, in order to predict during a crisis the future trends and impact of a certain event, such methods are inappropriate. Thus, this current study evaluates the COVID-19 shock on the economic development and the 
energy consumption in Pakistan using the system dynamic model. It is able to forecast the impact of the COVID-19 shock uncertainty on economic growth, energy consumption, and temperature.

\section{Data and methodology}

\section{Data}

This study analyzes the impact of COVID-19 pandemic shock on GDP. In addition to this, the nexus among energy consumption, GDP growth, and climate change for the period from 2001 to 2018 projecting the situation until 2032 are investigated. Time series secondary data have been taken from the National Transmission and Despatch Company (NTDC) and World Development Indicators (WDI). This study employed the system dynamics (SD) as it is being recognized as one of the powerful tools for addressing issues, especially where the relationship is complex. This methodology has been exploited in a limited manner for the case of Pakistan. The present research will provide a deeper insight into the specific issues on the matter. For the analysis, first, we developed a conceptual model showing the causal relationship among variables and followed by a Stella built model to retrieve the results. Table 1 summarizes the descriptive statistics. The mean values of GDP, energy consumption, population, and temperature are $184.57,67070.44,0.178$, and 20.798, respectively. The GDP and population values are in billions, while the units of energy consumption and temperature are Gwh and degree centigrade, respectively. All variables are positively skewed, which signifies more change over time. The kurtosis values are less than 3 , suggesting that these macro variables are less volatile. The Jarque-Bera results signify that the variables are normally distributed.

\section{Empirical methodology}

\section{Conceptual model showing causal loop}

For the model, the variables considered are GDP, energy consumption, and temperature as a proxy for climate change.
COVID-19 has been considered as the exogenous shock that will affect GDP during the projection period. The conceptual relationship has been displayed in Fig. 1. The literature shows there is a bidirectional relationship between the two variables. Furthermore, climate change is affecting energy consumption as well as GDP growth. The GDP growth is reinforcing energy consumption and vice versa. However, the COVID-19 is showing a balancing effect-meaning that GDP growth would be decreased. The literature is showing a bidirectional relationship between climate change and energy consumption.

\section{Energy consumption model}

The stocks and flows have been developed to build a Stellabased SD model. Stocks for GDP, energy consumption, population, and temperature have been taken with the initial values given in the following equations. GDP growth, energy consumption growth, temperature growth, and population growth are representing the flows of the model. The average annual growth rates have been calculated to compute the growth level of the selected variables. Per capita energy consumption is an additional auxiliary variable to check the trends in energy consumption. Four additional auxiliary variables have been incorporated to investigate the effect of these variables on one another: GDP affecting energy consumption, energy consumption affecting GDP, and energy consumption affecting climate change in the country. Figure 2 illustrates the energy consumption model.

\section{Mathematical model}

Table 2 summarizes the variables and equations used to check the relationship among variables using the system dynamic model. The following equations have been formulated to run the model for the period 2001-2032.

\section{Empirical outcomes}

The COVID-19 outspread crippled the world economy and has a devastating effect on all fields of life. This study tests the impact of the COVID-19 shock on the GDP forecasts and

Table 1 Descriptive statistics

\begin{tabular}{lllll}
\hline & GDP & Energy consumption & Population & Temperature \\
\hline Mean & 184.5724 & 67070.44 & 0.178021 & 20.79754 \\
Std. dev. & 79.75751 & 14571.02 & 0.020781 & 0.447281 \\
Skewness & 0.084361 & 0.072305 & 0.073021 & 0.424858 \\
Kurtosis & 1.791764 & 2.508426 & 1.798909 & 2.710614 \\
Jarque-Bera & 1.116227 & 0.196918 & 1.097961 & 0.604321 \\
\hline
\end{tabular}

Source: Author computation 
Fig. 1 Conceptual model showing causal loop

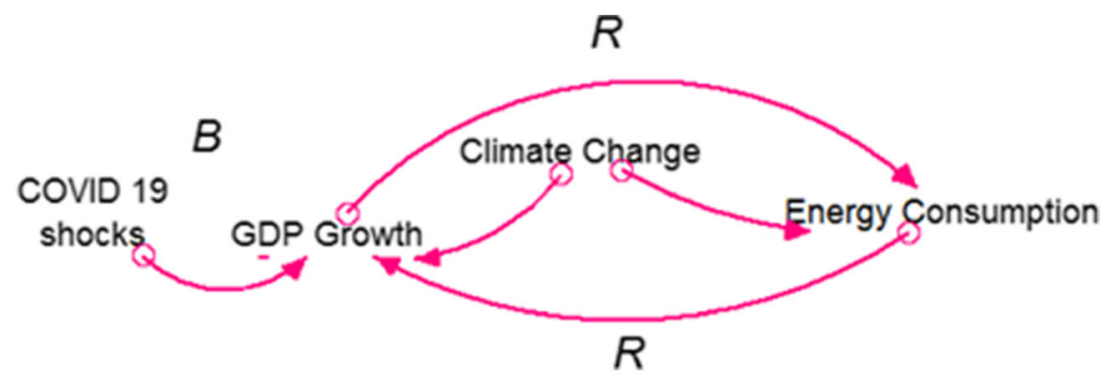

the expected economic losses and estimates the recovery time. Similarly, the lockdown situation reduces energy demand and consumption, detruding the GDP, where energy policy planning is mainly linked to GDP growth (Jamil and Ahmad 2010). Energy consumption and climate change relationship are well documented in the literature (Martínez 2015; Parajuli et al. 2019; Vasylieva et al. 2019; Zaharia et al. 2019). This study also tests and forecasts on how to abate in energy consumption due to this apneic situation that will affect climate change in Pakistan.

\section{Model validation}

Before projecting the situation for the 2021-2032 period, the model data requires validation. For the validation, all projected and actual values of energy consumption, GDP, and temperature are plotted to inspect the validity of the model visually. The trends in Fig. 3 (a, b, c) graphs show that the model data can be used for projection. The black dotted lines are actual data, whereas blue lines in Fig. 3 are representing the model data.

\section{COVID-19 and GDP}

The empirical results from COVID-19 impact on GDP are illustrated in Fig. 4. The results reveal that the presence of the virus will reduce the GDP growth rate by $1.35 \%$ in 2020. The outcome is consistent with the IMF forecast of $1.5 \%$ declines in the GDP (International Monetary Fund 2020). This effect will not end in 2020, but its adverse effect will also slow down the economic phase in the coming years. The yearly percentage decline en route dampens the GDP by $1.32 \%$ in 2021 and with an annual average of $1.25 \%$ in the next 4 years. The pandemic situation mainly hits the industries

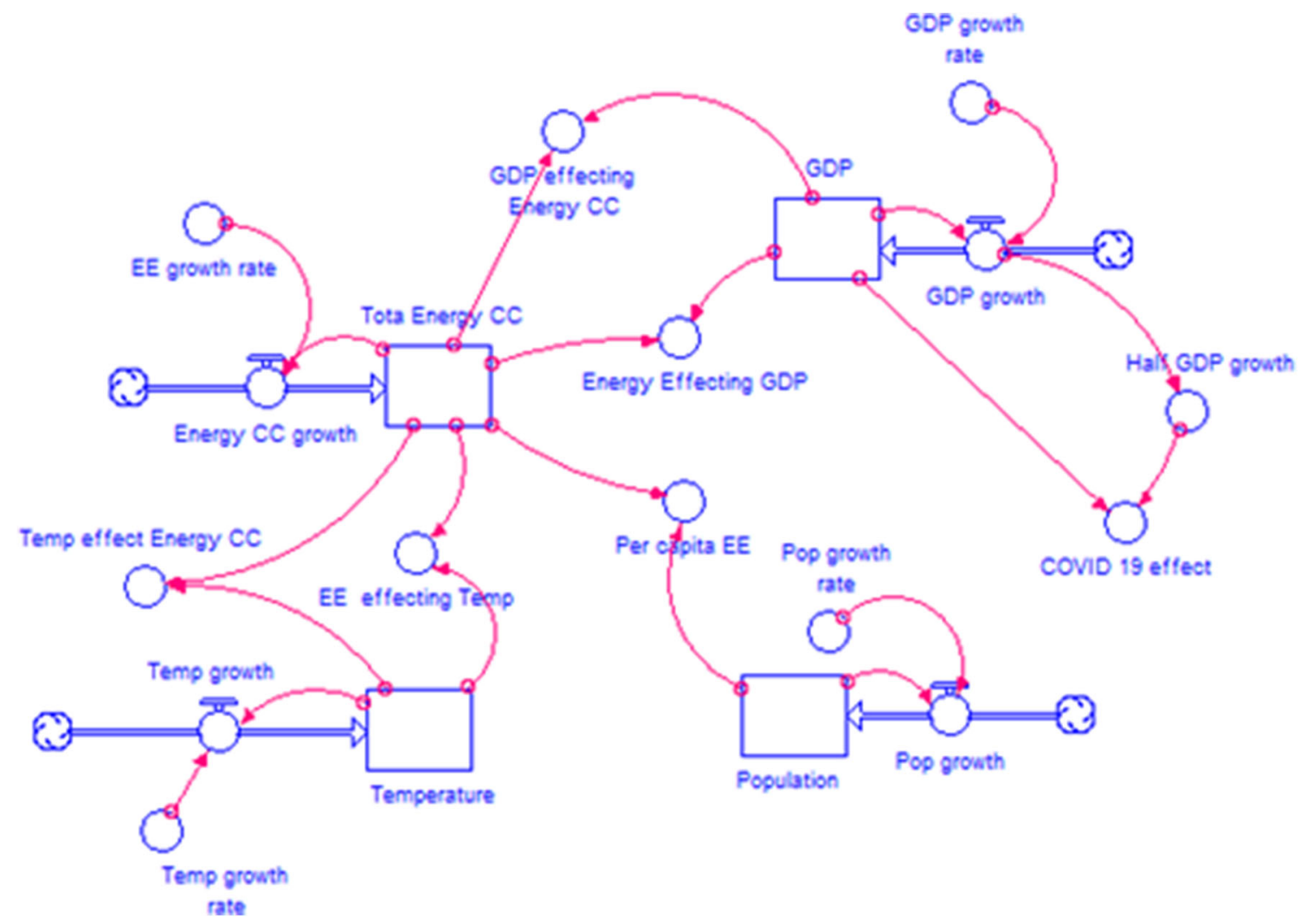

Fig. 2 System dynamic model - energy consumption, GDP, and climate change 
Table 2 Model equation and variables

\begin{tabular}{|c|c|}
\hline Variables & Equations \\
\hline \multirow[t]{2}{*}{ GDP $(\mathrm{t})$} & GDP $(\mathrm{t}-\mathrm{dt})+(\mathrm{GDP}$ growth $) * \mathrm{dt}$ \\
\hline & GDP average annual growth rate $=0.1$ \\
\hline GDP growth & GDP growth rate * GDP \\
\hline Population ( $\mathrm{t}$ ) & Population $(\mathrm{t}-\mathrm{dt})+($ Pop growth $) * \mathrm{dt}$ \\
\hline Pop growth & Pop growth rate*Population \\
\hline Temperature $(\mathrm{t})$ & Temperature $(\mathrm{t}-\mathrm{dt})+($ Temp growth $) * d t$ \\
\hline Temp growth & Temp growth rate*Temperature \\
\hline Energy consumption $(t)$ & Energy Consumption $(\mathrm{t}-\mathrm{dt})+($ Energy Consumption growth $) * d t$ \\
\hline Energy consumption growth & Energy Consumption growth rate* Energy Consumption \\
\hline Per capita energy consumption & Energy Consumption /Population \\
\hline COVID-19 affecting GDP & IF time $<2020$ then GDP else GDP- Half GDP growth \\
\hline Energy consumption temp & $\begin{array}{l}\text { IF Time }<2019 \text { then Temperature else } 0.00002 * \text { Energy Consumption } \\
\quad+19.78\end{array}$ \\
\hline $\begin{array}{l}\text { Energy consumption affecting } \\
\text { GDP }\end{array}$ & IF Time $<2019$ then GDP else $5.5^{*}$ Energy Consumption -181090 \\
\hline $\begin{array}{l}\text { GDP affecting energy } \\
\text { Consumption }\end{array}$ & IF Time $<2019$ then Energy Consumption else $0.173 *$ GDP +35399.22 \\
\hline Temp affecting energy & IF Time $<2019$ then Energy Consumption else \\
\hline Consumption & $16078.16 *$ Temperature-267316 \\
\hline Energy consumption growth Rate & 0.049 \\
\hline Energy growth rate & 0.049 \\
\hline GDP growth rate & 0.1 \\
\hline Pop growth rate & 0.022253 \\
\hline Temp growth rate & 0.003 \\
\hline INIT GDP & 72310 \\
\hline INIT population & 145.978402 \\
\hline INIT temperature & 20.78 \\
\hline INIT energy consumption & 43384 \\
\hline
\end{tabular}

and SMEs of the country. SME's contribute $40 \%$ of GDP, $46 \%$ of exports, $80 \%$ of non-agricultural employment, and $5 \%$ in the local value addition. Out of 3.8 million SMEs, 0.95 million will not survive more than a month lockdown putting 6.5 million jobs at risk (SDPI 2020). The major negative spike in Fig. 4 is during 2026, when the decline will be $\$ 6313.76$ million of total GDP. This is due to higher demand in the energy sector.

Pakistan's economy is facing severe financial and energy crises since 2007, which causes a GDP loss of $2.5 \%$ every year (Aziz and Ahmad 2015). The Chinese government initiated the CPEC projects under the belt and road initiative and invested $\$ 62$ billion. The successful completion of these projects will increase economic activity, create more jobs, uplift the production capacity, and improve the liquidity situation in the country (Khurshid et al. 2020). The major projects will be completed after 2020. However, the pandemic will probably cause further delays in the completion of these projects. This energy shortfall, along with increasing future demand will negatively affect the industrial production and employment that already caused $7.5 \%$ unemployment, and $40 \%$ of industries are closed since 2007 (Aziz and Ahmad 2015). Moreover, COVID-19 will reduce the flow of financial resources and will add further pressure on the GDP. Timely policy measures can help in defusing the situation quickly.

\section{Energy consumption/shortfall and GDP}

The energy demand-supply and shortfall can be seen in Fig. 5 . The energy shortfall in 2011 was $3984 \mathrm{MW}$ and mounted to $5454 \mathrm{MW}$ in 2018 (NTDC 2018). This was due to the steady growth of $7.1 \%$ during 2001-2007 and rural electrification (World Bank 2017). Figure 6 explains the GDP losses due to increasing energy demand. The results illustrate that the pandemic will reduce the energy consumption that will also lower the demand-side pressure in 2020. However, the lockdown will affect the completion of all energy projects, widen the demand-supply gap, and worsen the supply side of the country in the coming years. The outcomes show that lower supply will cause a GDP loss of $\$ 23,458.3$ million in 2020 . 


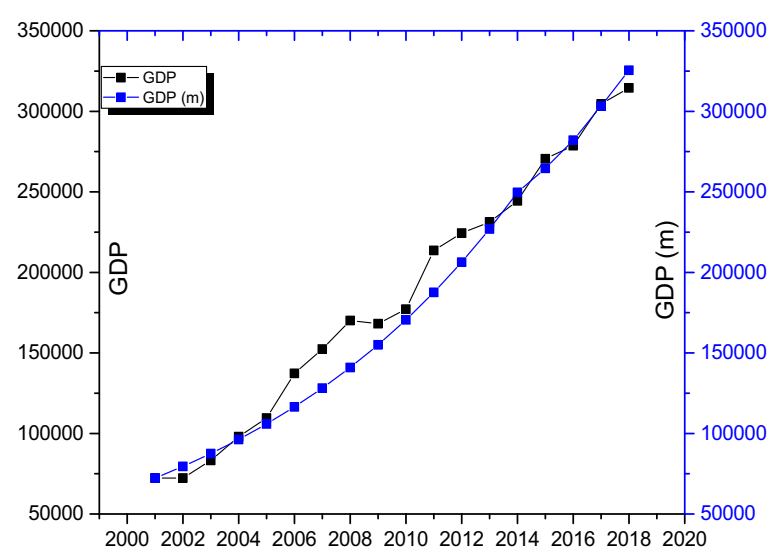

(a) Actual \& Model data of GDP

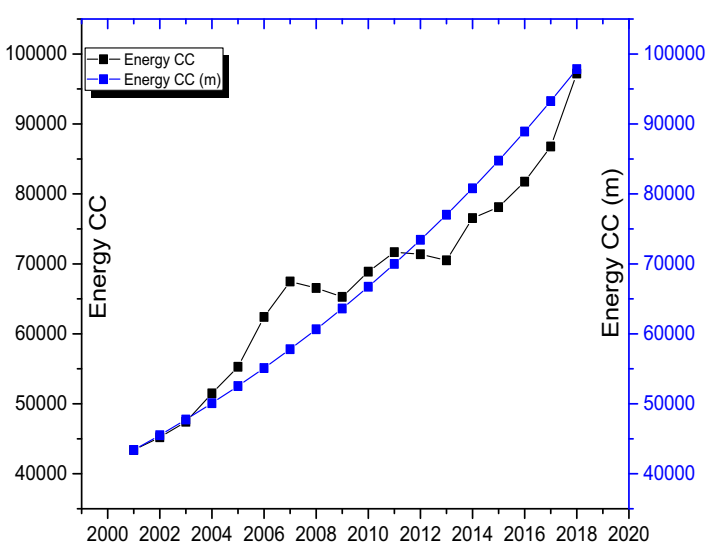

(b) Actual \& Model data of Energy CC

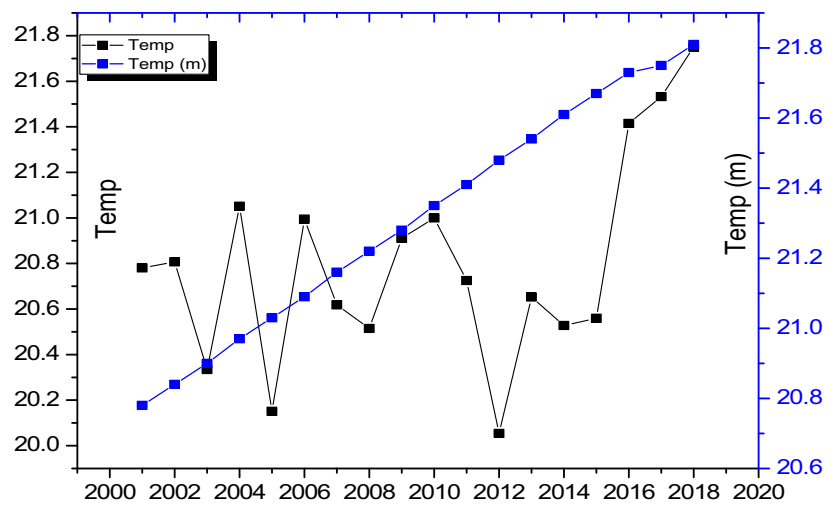

(c) Actual \& Model data of Temperature

Fig. 3 (a) Actual and model data of GDP. (b) Actual and model data of energy CC. (c) Actual and model data of temperature

Fig. 4 COVID-19 shock and GDP loss

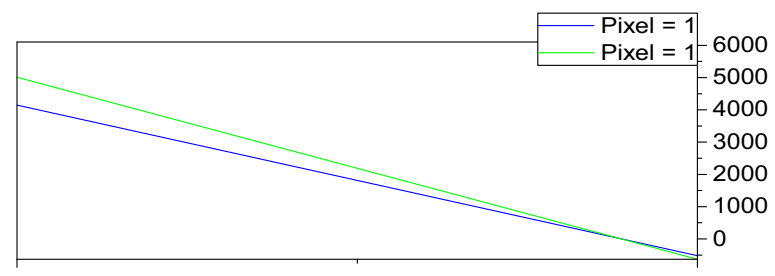

COVID-19 and GDP

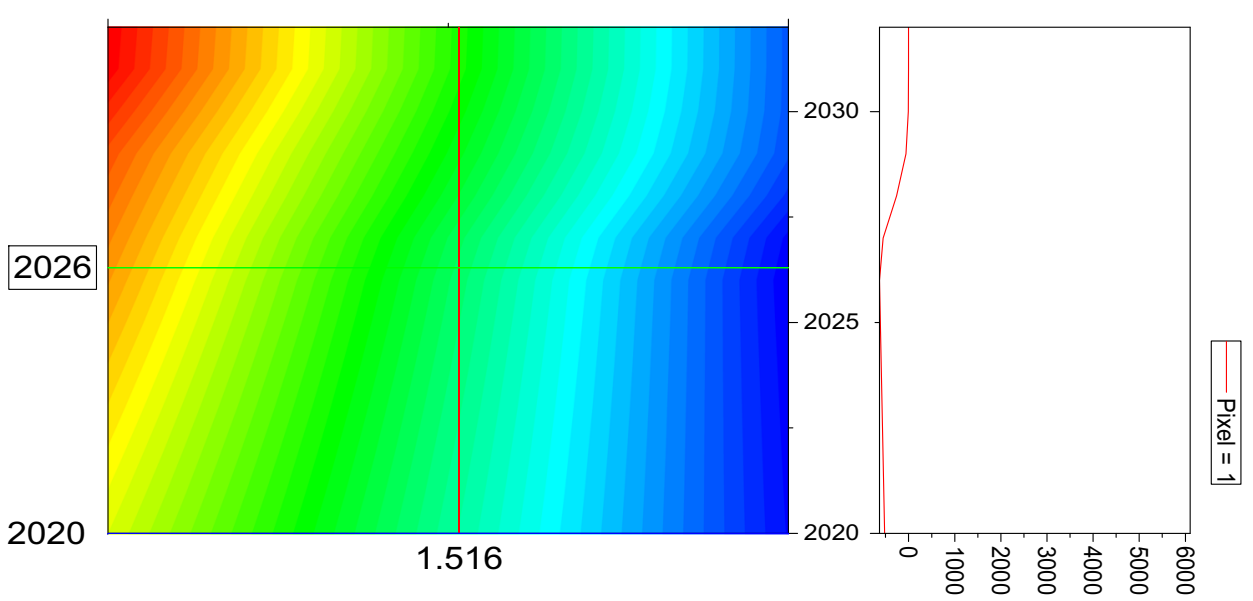


Fig. 5 Electricity shortfall


The effect will become more intense from 2025 to 2028 , with an annual average GDP loss of $\$ 54,238$. The shortfall caused a GDP loss of $2.5 \%$ in 2018. The GDP losses due to the energy sector will be $5.6 \%$ of GDP in 2020 , and the number will rise to $10.3 \%$ in 2028 . These outcomes are subject to the delay or on the timely completion of all major energy projects. The ongoing major energy projects will be completed before 2026. The delay in the completion of energy projects will worsen the situation and prolong the deficit period (Kazmi 2016).

\section{Energy consumption and climate change}

Figure 7 exhibits the nexus between energy consumption and climate change in Pakistan. The empirical literature concludes that energy consumption has a positive effect on climate change and $\mathrm{CO} 2$ emission in Pakistan (Mirza and Kanwal 2017; Ali et al. 2019). The outcomes of this study reveal that due to the COVID-19 pandemic and lower energy consumption, the average temperature will decrease in the country. During 2020 and 2021, the average temperature will drop by 0.05 and $0.02{ }^{\circ} \mathrm{C}$, respectively. There is a slight rise in the average temperature from 2023 to 2028 . The average temperature during this period will increase by $0.041{ }^{\circ} \mathrm{C}$. The results are consistent with the previous model; that is, Pakistan will have an energy shortage until 2028 and will not fulfill the required domestic demand. The average annual temperature from 2029 to 2032 will raise to $0.18^{\circ} \mathrm{C}$. The growth rate of the said periods was recorded at $20.3 \%$. The average growth of temperature is much higher than the historical data.
Fig. 6 Energy consumption and GDP

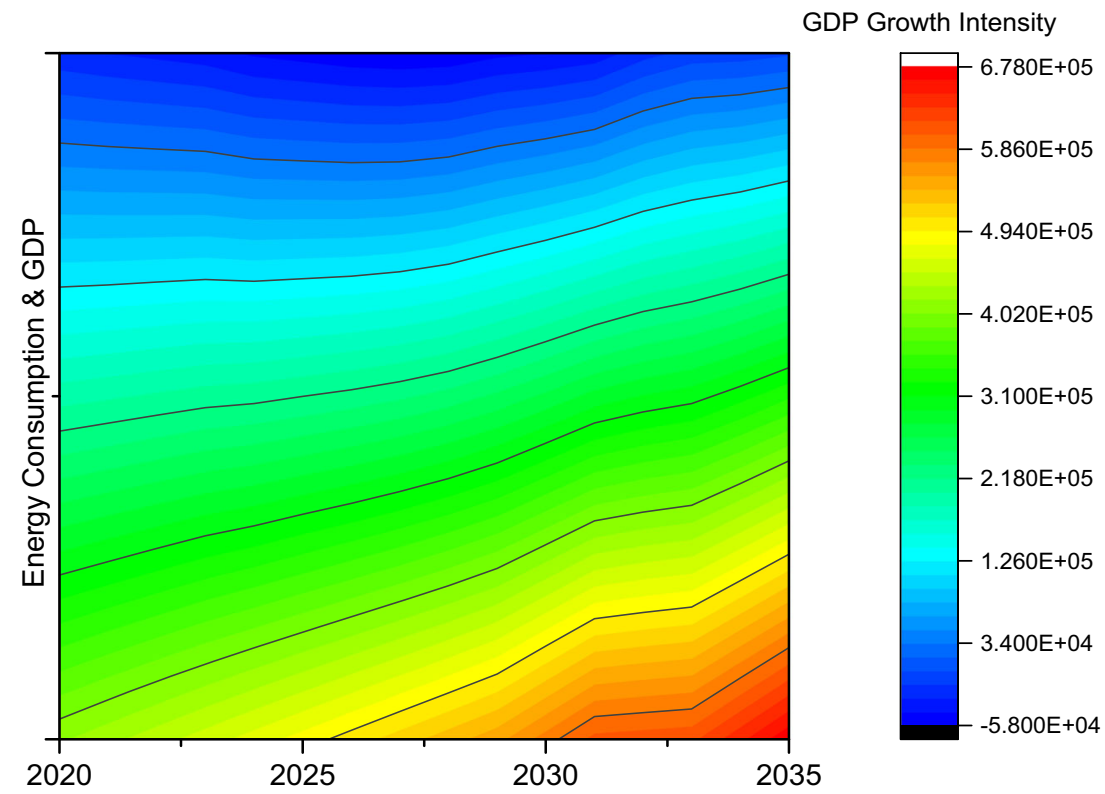


Fig. 7 Energy consumption and climate change

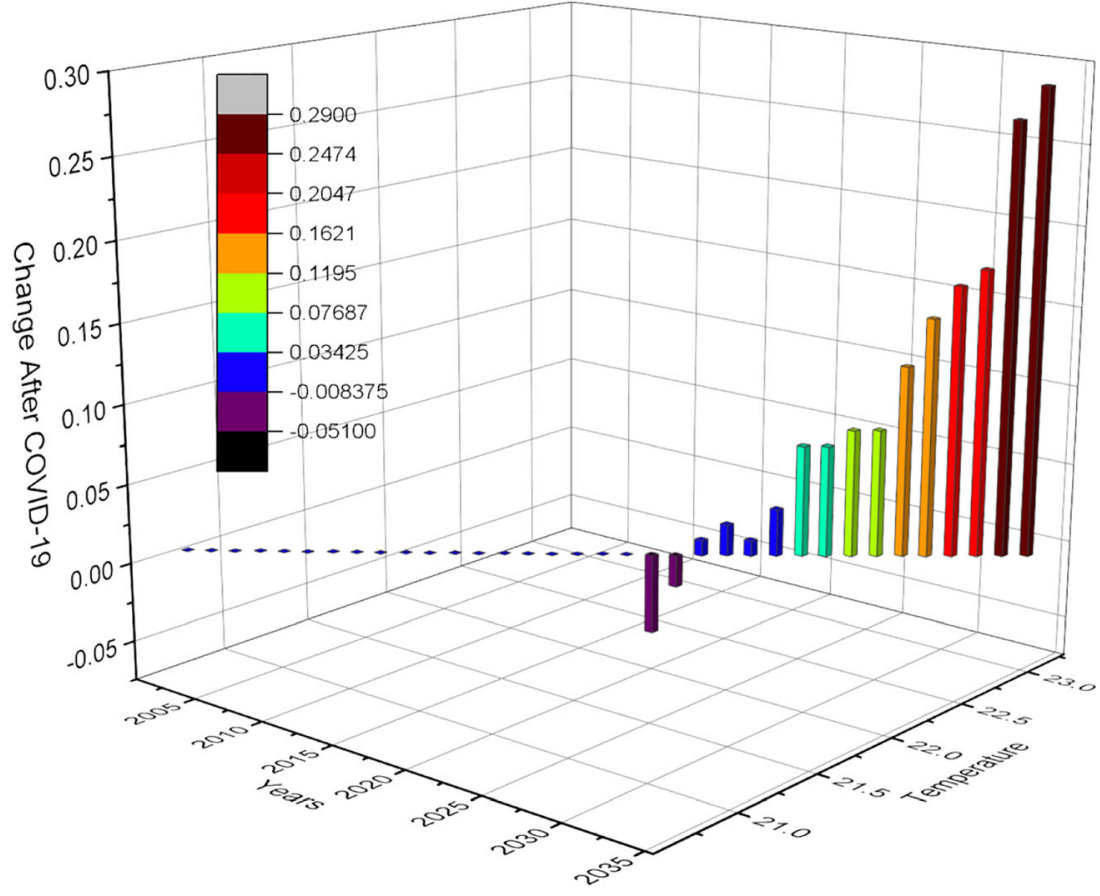

In sum, the COVID-19 pandemic has both a direct and indirect effects on the Pakistani economy. The lockdown situation will affect the real outputs and indirectly will affect all other sectors of this developing country. The only positive thing that comes from the pandemic is its environmental effect. The results show that it will decrease the temperature and greenhouse gas emission.

\section{Conclusion and policy implications}

This study analyzes the impact of the COVID-19 pandemic shock on GDP. Moreover, we tested the relationship between energy consumption, GDP growth, and climate change for the period ranging from 2001 to 2018 and projected the situation until 2032 using a system dynamic modeling approach. The pandemic shock created a lockdown situation that ceases the operations of the economy, severely affecting real outputs and the GDP. The outcomes reveal that this shock will depress the GDP growth rate by $1.35 \%$ in 2020 . Besides, the negative effect will slow down the economic phase until 2029 in the absence of timely measures both on the fiscal and monetary side. The pandemic shock will reduce the GDP by $1.32 \%$ in 2021 and with an annual average of $1.25 \%$ in the next 4 years. The negative spike will decline the GDP by $\$ 6313.76$ million in 2026. The electric shortfall of $5454 \mathrm{MW}$ and delay in the ongoing energy projects will cost $5.6 \%$ of GDP loss in 2020 , and the number will mount to $10.3 \%$ in 2028 . However, the lockdown and energy consumption will positively affect environmental aspects. The average temperature in 2020 and 2021 will drop by 0.05 and $0.02{ }^{\circ} \mathrm{C}$. The following policy measures can help in the pandemic situation to reduce the GDP losses.

The current situation is quite different from what economies have faced in the last century. The challenges are both economic and epidemic, given the fact that the country has been put on quarantine. The government has to make timely decisions; otherwise, the above factors may lead the country towards recession. In the absence of effective policy measures, this recession may even drive the country at the threshold of depression.

The Pakistani government has to take both supply and demand-side measures to divert the economy from the recession path. The government must increase spending and reduce the lending rate (currently 8.53, highest in the region) and corporate and income taxes.

The major Hydro energy project (30,000MW capacity) with local and foreign investments was under construction in less dense and extreme northern and southern regions of Pakistan. The government should immediately start operations of developmental projects shut down due to COVID-19. It will help in reducing the energy gap, lessen the possible GDP losses due to excessive demand, provide employment, and increase the circulation of money.

Low oil and gas prices provide an opportunity to implement the structural reform in carbon mitigation efforts. The decline in oil prices provides an opportunity to reduce fossil fuel subsidies and implement an extensive carbon pricing mechanism. It will drive the economy towards a low carbonintensive direction. Government incentive packages should aim for decarburization and discourage the high emitting projects. 
The government must lockdown the affected areas and, at the same, time relax the industries of the less affected regions with tight SOPs. If not, Pakistan's industries and SMEs cannot survive long in this situation that will severely affect the GDP. SMEs in Pakistan are the backbone of the economy. Measures such as financial support and them getting back to the supply chain can secure jobs and reduce possible GDP losses.

\section{References}

Akpan UF, Akpan GE (2012) The contribution of energy consumption to climate change: a feasible policy direction. International Journal of Energy Economics and Policy, 2(1), 21-35. https://www. researchgate.net/profile/Usenobong_Akpan/publication/ 227411028 The Contribution of Energy Consumption to Climate ChangeA Feasible Policy Direction/links/ 54d47fa60cf2970e4e63498b/The-Contribution-of-EnergyConsumption-to-Climate-ChangeA-Feasible-Policy-Direction.pdf/ (assessed on April 20, 2020)

Akram N (2013) Is climate change hindering economic growth of Asian economies? Asia-Pacific Dev J 19(2):1-18

Akram N, Hamid A (2015) Climate change: A threat to the economic growth of Pakistan. Prog Dev Stud 15(1):73-86

Alfredsson EC (2004) "Green" consumption - no solution for climate change. Energy 29(4):513-524

Ali H, Malik AM, Siddique HMA, Rizwan M (2019) Impacts of urbanization and energy consumption on climate change in Pakistan. https://www.researchgate.net/publication/338884634_IMPACTS OF URBANIZATION AND ENERGY CONSUMPTION ON CLIMATE_CHANGE_IN_PAKISTAN/ (assessed on April 18, 2020)

Ashraf Z, Javid AY, Javid M (2013) Electricity consumption and economic growth: evidence from Pakistan. Econ Business Lett 2(1):2132

Asteriou D, Price S (2005) Uncertainty, investment and economic growth: evidence from a dynamic panel. Rev Dev Econ 9(2):277288

Atif, S. M., \& Siddiqi, M. W. (2010). The electricity consumption and economic growth nexus in Pakistan: a new evidence. https://doi.org/ $10.2139 / \mathrm{ssrn} .1569580$

Aziz R, Ahmad MB (2015) Pakistan's power crisis. Special report. United States Institute of Peace. http://www.usip.org/sites/default/ files/SR375-Pakistans-Power-Crisis-The-Way-Forward.pdf/ (assessed on 25/05/2020)

Aziz, S., Burki, S. J., Ghaus-Pasha, A., Hamid, S., Hasan, P., Hussain, A., ... \& Sherdil, A. Z. K. (2010). Third annual report-state of the economy: pulling back from the abyss (p. 66). Lahore, Pakistan: Beaconhouse National University, Institute of Public Policy

Bloomberg Green (2020) A Pandemic that cleared skies and halted cities isn't slowing global warming. Bloomberg Green, May 7, 2020. https://www.bloomberg.com/graphics/2020-how-coronavirusimpacts-climate-change/ (assessed on 25/05/2020).

Chen PY, Chen ST, Chen CC (2012) Energy consumption and economic growth - new evidence from meta-analysis. Energy Policy 44:245255

Christensen P, Gillingham K, Nordhaus W (2018) Uncertainty in forecasts of long-run economic growth. Proc Natl Acad Sci 115(21): 5409-5414

das Neves Almeida TA, Cruz L, Barata E, García-Sánchez IM (2017) Economic growth and environmental impacts: An analysis based on a composite index of environmental damage. Ecol Indic 76:119-130
Economic Survey (2018) Finance Division, Government of Pakistan, Islamabad, Pakistan. Economic Survey of Pakistan, 2017-18. http://www.finance.gov.pk/survey/chapters_19/Economic_Survey_ 2018 19.pdf/ (assessed on 25/05/2020).

Farooq A, Yasmin B (2017) Fiscal policy uncertainty and economic growth in Pakistan: Role of financial development indicators. J Econ Cooperation Dev 38(2): 1

Fatima A, Waheed A (2014) Economic uncertainty and growth performance: a macroeconomic modeling analysis for Pakistan. Qual Quant 48(3):1361-1387

Gozgor G, Lau CKM, Lu Z (2018) Energy consumption and economic growth: New evidence from the OECD countries. Energy 153:2734

Hao Y, Zhu L, Ye M (2018) The dynamic relationship between energy consumption, investment and economic growth in China's rural area: new evidence based on provincial panel data. Energy 154: 374-382

International Finance Corporation (2017) Pakistan off-grid lighting consumer perceptions Study Overview, Retreived from: https://www. ifc.org/wps/wcm/connect/d72aa0004886746d8388f7299ede9589/ Pakistan+Solar+Consumer+Study+Overview 26thMay2015 LQ. pdf?MOD=AJPERES/ (assessed on April 17, 2020)

International Monetary Fund (2020) 2020 Projected real GDP by International Monetary Fund. https://www.imf.org/en/Countries/ PAK/ (assessed on April 17, 2020)

Jamil F, Ahmad E (2010) The relationship between electricity consumption, electricity prices and GDP in Pakistan. Energy Policy 38(10): 6016-6025

Javid M, Qayyum A (2014) Electricity consumption-GDP nexus in Pakistan: a structural time series analysis. Energy 64:811-817

Kazmi STH (2016) China's journey in renewable energy and its potential spillover effects through the CPEC in Pakistan. Pak Dev Rev:619 631

Khurshid A, Kedong Y, Calin AC, Zeldea CG, Qiang S, Wenqi D (2020) Is the relationship between remittances and economic growth influenced by the governance and development of the financial sector? New Evidence from the Developing Countries. Journal for Economic Forecasting 1:37-56

Lensink R, Bo H, Sterken E (1999) Does uncertainty affect economic growth? An empirical analysis. Weltwirtschaftliches Arch 135(3): 379-396

Li Y, Pizer WA, Wu L (2019) Climate change and residential electricity consumption in the Yangtze River Delta, China. Proc Natl Acad Sci $116(2): 472-477$

Lu WC (2017) Electricity consumption and economic growth: evidence from 17 Taiwanese industries. Sustainability 9(1):50

Mahmood T, Kanwal F (2017) Long run relationship between energy efficiency and economic growth in Pakistan: Time series data analysis. Forman J Econ Stud 13:105-120

Martínez CIP (2015) Energy and sustainable development in cities: A case study of Bogotá. Energy 92:612-621

Mgbemene CA (2011) The effects of industrialization on climate change. In Fulbright Alumni Association of Nigeria 10th Anniversary Conference Development, Environment and Climate Change: Challenges for Nigeria, University of Ibadan (pp. 12-15).

Mirza FM, Kanwal A (2017) Energy consumption, carbon emissions and economic growth in Pakistan: Dynamic causality analysis. Renew Sust Energ Rev 72:1233-1240

Nordhaus WD (2013) The climate casino: Risk, uncertainty, and economics for a warming world. Yale University Press

NTDC (2018) Power System Statistics 43rd Edition-2018. NATIONAL TRANSMISSION \& DESPATCH COMPANY. https://www.ntdc. com.pk/ntdc/public/uploads/services/planning/power\%20system\% 20statistics/pss\%2043rd\%20Edition.pdf/ (assessed April 18, 2020) 
Ozturk I, Aslan A, Kalyoncu H (2010) Energy consumption and economic growth relationship: Evidence from panel data for low and middle income countries. Energy Policy 38(8):4422-4428

Parajuli R, Joshi O, Maraseni T (2019) Incorporating forests, agriculture, and energy consumption in the framework of the Environmental Kuznets Curve: a dynamic panel data approach. Sustainability 11(9):2688

Qiang S, Khurshid A, Calin AC, Khan K (2019) Do Remittances Contribute to the Development of Financial Institutions? New Evidence from the Developing World. Romanian J Econ Forecast 22(2):78

Rathnayaka RKT, Seneviratna DMKN, Long W (2018) The dynamic relationship between energy consumption and economic growth in China. Energy Sources, Part B: Economics, Planning, and Policy 13(5):264-268

Rehman A, Deyuan Z (2018) Investigating the linkage between economic growth, electricity access, energy use, and population growth in Pakistan. Appl Sci 8(12):2442

SDPI (2020) PROJECTED IMPACT OF LOCKDOWN ON SMEs IN PAKISTAN, Sustainable Development Policy Institute (SDPI), COVID-19 POLICY REVIEW SERIES. https://sdpi.org/wpcontent/uploads/2020/04/COVID-19-Impact-of-Lockdown-onSMEs.pdf/ (assessed on April 20, 2020)

Shahbaz M, Zakaria M, Shahzad SJH, Mahalik MK (2018) The energy consumption and economic growth nexus in top ten energyconsuming countries: Fresh evidence from using the quantile-onquantile approach. Energy Econ 71:282-301
Siddiqui R (2004) Energy and economic growth in Pakistan. Pak Dev Rev 43:175-200

Sušjan A, Redek T (2008) Uncertainty and growth in transition economies. Rev Soc Econ 66(2):209-234

Vasylieva T, Lyulyov O, Bilan Y, Streimikiene D (2019) Sustainable economic development and greenhouse gas emissions: The dynamic impact of renewable energy consumption, GDP, and corruption. Energies 12(17):3289

WIRED (2020) How is the coronavirus pandemic affecting climate change? WIRED. https://www.wired.com/story/coronaviruspandemic-climate-change/ (assessed on 25/05/2020)

World Bank (2017) World Bank Economic Indicators Pakistan. http:// data.worldbank.org/indicator/NY.GDP.MKTP.KD.ZG?locations= $\mathrm{PK} /$ (assessed April 18, 2020)

World Bank (2020) Does GDP growth necessitate environmental degradation? World Bank Blogs, January 14, 2020. https://blogs. worldbank.org/opendata/does-gdp-growth-necessitateenvironmental-degradation/ (assessed on 25/05/2020)

Zaharia A, Diaconeasa MC, Brad L, Lădaru GR, Ioanăş C (2019) Factors Influencing Energy Consumption in the Context of Sustainable Development. Sustainability 11(15):4147

Publisher's note Springer Nature remains neutral with regard to jurisdictional claims in published maps and institutional affiliations. 